\title{
ENCUENTROS EN LA GRAN MEDIADORA: CANDIDO Y CUBA
}

\author{
Jorge Fornet \\ Centro de Investigaciones Literarias de la Casa de las Américas, La Habana, Cuba \\ direccioncil@casa.cult.cu
}
"Para nosotros, brasileños, generalmente tan separados de los hermanos de habla española, Cuba ha sido la gran mediadora $[\ldots]$ "

Antonio Candido

Precedido por la publicación en 1971 de su Introducción a la literatura del Brasil, llegó Antonio Candido a Cuba algunos años después. La Casa de las Américas había decidido refundar su colección Nuestros Países (dedicada hasta entonces a "breves presentaciones histórico-geográficas de los países de nuestra América") con la edición de aquel librito que abría la colección a "la vasta problemática latinoamericana, aunque siempre con el destino escolar" que tuvieron los títulos anteriores, como se expresaba en una advertencia en su página inicial. Si bien estas notas mías debieron centrarse en el impacto que desde entonces tuvo Candido en Cuba, en las lecturas que generó su obra y la posible influencia en el quehacer crítico de la isla -como parte de su presencia mayor en el ámbito hispanome limitaré al objetivo mucho más modesto de recordar algunos puntos de encuentro, como preámbulo a un estudio mayor de la relación entre uno y otra.

La aparición en Cuba del breve pero iluminador estudio de Candido no salía de una chistera ni caía en el vacío. Más de una vez se ha recordado que cuando la Casa de las Américas abrió en 1963 su colección de clásicos "Literatura Latinoamericana", el título inaugural fue Memorias póstumas de Blas Cubas, de Machado de Assis. También es de sobra conocido que al año siguiente el nombre original del certamen convocado por la institución, que hasta entonces había sido Concurso Literario Hispanoamericano, sería sustituido por el de Concurso Literario Latinoamericano (y a la postre, simplemente, como Premio Literario) con el propósito de incluir a los escritores brasileños. Ello formaba parte de un propósito integrador que ya Ernesto Che Guevara mencionaba en el discurso que pronunciara en la Conferencia de Punta del Este, en 1961, al reconocer al Premio como prueba y ejemplo de la "exaltación [que Cuba propiciaba] del patrimonio cultural de nuestra América Latina”. 
Tanto un gesto como otro muestran el punto al que la Casa de las Américas estaba llegando para borrar el Tratado de Tordesillas simbólico que solía separar a Hispanoamérica de Brasil. Lamentablemente, el golpe de Estado contra el presidente João Goulart dificultó la presencia de escritores brasileños en la Casa, que no se haría estable y masiva en términos del concurso hasta 1980. No fue sino hasta entonces que se convocaría la literatura brasileña como categoría independiente dentro del Premio Literario.

No es un hecho menor, por cierto, que en el mismo 1964 en que se iniciaba un acercamiento inédito al universo brasileño, se estaba dando desde la institución cubana el disparo de arrancada de lo que sería el boom, con aquel célebre número de la revista Casa de las Américas coordinado por Ángel Rama. El número en cuestión fue el 26, de octubre-noviembre de ese año, el cual incluyó textos de Carpentier, Onetti, Cortázar, Sábato, Fuentes y Vargas Llosa, así como textos críticos sobre estos y otros autores. Tal selección estuvo precedida por el largo ensayo del propio Rama, "Diez problemas para el novelista latinoamericano", que había leído ya en la Casa de las Américas. Se trataba, diría años después en su prólogo a Novísimos narradores hispanoamericanos en Marcha, 1964/1980 (1981), del "intento de razonar orgánicamente las diversas vías que había tomado un género que, imprevistamente fecundado por la rica poesía de los vanguardistas y por la novela norteamericana, había respondido a las demandas del exaltado pueblo de los años sesenta" (Rama 457).

Según la versión de Rama, fue él mismo quien, consciente del especial avance de la narrativa latinoamericana, propuso a Casa consagrar un número a esa impetuosa producción que habría de ser bautizada -según él, desdichadamente-con el nombre de boom. Precisamente en aquel 1964 la nueva narrativa "cobró reconocida carta de ciudadanía en toda América" (18), afirmaría Rama, tanto con el ensayo aparecido en Casa de las Américas como con su prólogo a una antología que preparó para el semanario Marcha; ambos textos, en tal caso, iniciaron "una estimación global y panorámica del movimiento". Es decir, que entonces se haría visible la madurez de la novelística a nivel continental.

Al dedicar un dossier al crítico uruguayo, a raíz de su muerte, con el título Ángel Rama, presencia que no acaba (en el número 192, de 1993), la revista Casa solicitó a Candido unas palabras que este nombró "Lucidez latinoamericana". Cuenta allí haber conocido a Rama "en el momento exacto en que tomó una decisión que, en el curso de los años, se tornó una verdadera misión. Era el comienzo de 1960 y me declaró que en lo adelante haría todos los esfuerzos necesarios para establecer contactos de todo tipo con los intelectuales de la América Latina". Rama, añade Candido, "estaba dispuesto a intercambiar correspondencia, libros, hacer reseñas, viajar, interesarse a fondo por la vida cultural de nuestro subcontinente. Como se sabe, fue lo que hizo [...]" (14). Ya es imposible saber cuán productivo habría resultado la coincidencia de aquella madurez de nuestra novelística (y el entusiasmo de Rama) con el acelerado acercamiento que la Casa de las Américas estaba propiciando con la literatura brasileña.

Lo cierto es que la ruptura del orden constitucional en Brasil provocó un distanciamiento difícil de calibrar. Pero quince años más tarde, es decir, en 1979, Antonio Candido viajó por primera vez a Cuba. Como he dicho, para entonces ya había sido publicada entre nosotros su Introducción a la literatura del Brasil, y los autores de ese país concursaban esporádicamente en el Premio Literario y eran jurados en él, si bien todavía no se había 
instaurado una categoría exclusiva para ellos, lo que sí había ocurrido desde 1976 para la literatura caribeña en inglés, y desde 1979 para la literatura caribeña de expresión francesa. Esa efectiva forma de integrar orgánicamente al Caribe dentro del quehacer de la Casa fue parte del natural proceso de integración regional que se había iniciado con la descolonización de las islas del Caribe anglófono. De manera que cuando Candido viajó a La Habana en 1979, como jurado del Premio Literario, la presencia de otras lenguas de la región en el certamen era ya una realidad, pero faltaría un año aún para que la literatura brasileña volviera a él con todo el despliegue que merecía.

Una encuesta realizada por la revista Casa en su número 114 de ese mismo 1979, a propósito de los veinte años del concurso, obtuvo la siguiente respuesta del crítico brasileño: "Al aceptar la invitación para participar como miembro del Jurado, manifestamos nuestro apoyo y nuestro aprecio por el gran esfuerzo cultural de Cuba socialista. Gracias a ella podemos convivir libremente con intelectuales de los diversos países latinoamericanos y caribeños sin la tradicional mediación de los países imperialistas". Para él, lo que esto representaba "como liberación de energías mentales" era inestimable, y de ahí "el clima de fraternidad y el rendimiento que caracterizan las actividades". Esas "verdaderas sesiones anuales de reflexión y análisis, complejas y serias [...] han contribuido y contribuirán cada vez más a definir criterios adecuados a una valoración correcta de la producción intelectual de la América Latina y de nuestros diferentes géneros" (21).

Se hacía obvio que el viaje a La Habana había implicado una profundización de los lazos entre Candido y la Isla, de los que daría pronto nuevos testimonios; tal es el caso de su presencia en un número de 1979 de la revista Encontros com a Civilização Brasileira, la cual dedicó un encarte al XX aniversario de la Revolución cubana, precedido por un largo y denso estudio de Florestan Fernandes y testimonios de algunos viajeros a Cuba. (El propio Fernandes, por cierto, publicaría ese mismo año el volumen Da guerrilha ao socialismo: a revolução cubana, y muchos años después, en 2006, Casa publicaría el trabajo de Candido "Florestan Fernandes marxista", en su número 202).

Sin embargo, el momento de mayor acercamiento entre Candido y la Casa de las Américas y, por extensión, con Cuba, se produjo en 1981 cuando fue invitado a pronunciar el discurso de constitución del jurado del Premio Literario (el cual se reprodujo en el número 126, de ese año, del órgano oficial de la institución). Allí expresaba que el hecho de que por primera vez un brasileño hablara en tales circunstancias, estaba lleno de significado, y respondía a la inclusión de la lengua portuguesa en el Premio como oportunidad para sus escritores de concursar en plano de igualdad con los de lengua española, francesa e inglesa, "expresando en su amplitud el horizonte cultural de la América Latina y el Caribe”. Después de reconocer cómo en los momentos más difíciles Cuba desarrollaba los trabajos "de este admirable centro que es la Casa de las Américas, uno de los instrumentos más nobles y eficaces de la integración cultural de la América Latina" (Discurso 5), pasa a una cuestión más profunda en la que me interesa detenerme.

Para él, la integración del Caribe de lengua inglesa, así como del Brasil, en el espacio del certamen literario, significaba "la consagración de un hecho escamoteado o desvirtuado por la visión imperialista y colonizadora, y que comienza a adquirir un nuevo sentido para la conciencia progresista de América". Ese hecho era el reconocimiento de una vasta unidad que articularía a los países marcados por la herencia africana, en sentido 
homólogo, dice, del que caracterizó la conciencia de la herencia indígena, lo cual altera "el esquema tradicional (y también oficial) de las concepciones que tomaban en cuenta, casi exclusivamente, la herencia europea del colonizador". En sus palabras inaugurales, Candido recordaba que "gracias a un gran esfuerzo cultural, centralizado inicialmente por México, se impuso al Continente la realidad y el ideal de una Indoamérica, destinados a enriquecer la perspectiva de un contrapunto cultural cuya idea rectora había sido hasta entonces, de manera a veces tiránica, la de la Euroamérica" (6).

Y si ese esfuerzo logró incorporar en nuestra manera de entendernos la herencia indígena, ahora - expresa el crítico-, gracias a Cuba, sentimos "como parte esencial de nuestro universo, el Caribe de tantas huellas africanas, completado por un nuevo modo de vincularnos a África". De tal modo, Cuba abre la nueva era "desarrollando la conciencia de una Afroamérica que será revalorizada en el conjunto del Continente, a un nivel de dignidad igual al de las demás herencias que componen nuestra realidad". Le parece coherente que un país revolucionario, que había eliminado las clases y liquidado al mismo tiempo las tiranías culturales, incorporara "a nuestro concierto social la presencia del mundo afroamericano". Así, "al contribuir de modo decisivo a traer al nivel de la conciencia de todos esa configuración cultural afroamericana, Cuba está delineando una figura especial en el conjunto de nuestra América" (6). No podemos olvidar-Candido no lo hace- que por entonces miles de militares y colaboradores cubanos se encontraban en África, particularmente en una Angola asediada por el régimen sudafricano del apartheid, y que en el discurso oficial la Isla se reconocía como latinoafricana. De manera que Candido percibe la sintonía entre una presencia y otra, pero destaca el aporte descolonizador que desde la institucionalidad literaria (específicamente desde un premio) se estaba haciendo al otorgar visibilidad y coherencia a un universo afro, normalmente preterido o desgajado del resto de los aportes históricos y culturales de nuestra región.

En todo caso, Candido percibe el potencial de la política de la Casa de las Américas (y del país), de la que él mismo formaba ahora parte protagónica, y lo reconoce de manera explícita: "Para nosotros, brasileños, generalmente tan separados de los hermanos de habla española, Cuba ha sido la gran mediadora, al crear la posibilidad de entendimientos que se forman aquí y se desarrollan fuera, y al tejer una red fraternal que abraza al Continente con sus posibilidades de comprensión e intercambio" (7).

Aunque no existe una correspondencia fluida entre Candido y la Casa de las Américas, sobre todo si se le compara con la copiosísima que se sostuvo con otros intelectuales (como el propio Rama, por ejemplo), hay varias cartas que dan cuenta del itinerario de una relación, y algunas curiosas como la que enviara el 18 de enero de 1982 con Fernando Henrique Cardoso, quien viajaba como jurado del Premio de ese año, labor para la que tal vez había sido sugerido por el propio Candido en su estancia del año anterior. "Chamo a atenção de vocês todos para a importancia da presença de Fernando Henrique, que considero um dos políticos brasileiros de maior capacidade, lucidez e honestidade", expresaba en aquella carta. Y añadía: "é provável que a carreira dele vá sempre para cima, até os mais altos níveis da República". De ahí que recomendara: "Acho que a sua visita a Cuba é um acontecimento, pela projeção política que ele tem [...]. E acho que vocês deveriam fazer o possível para pô-lo em contacto com as mais alta [sic] cúpulas dirigentes. Se possível, a mais alta". 
Al año siguiente, en 1983, la revista Casa de las Américas reprodujo en su número 136 el reconocido e influyente ensayo de Candido titulado "Los brasileños y la literatura latinoamericana" (que la publicación habanera tomó de la revista Novos Estudos). En su incisivo acercamiento al tema, Candido hacía notar la frontera, con frecuencia sutil, con que suele separarse a la América Latina entre las diecinueve naciones hispanoamericanas, de un lado, y su propio país, del otro. "Es curioso", señalaba al inicio de su intervención, "que en el temario de este encuentro el único país expresamente mencionado sea el Brasil. Los otros tópicos aluden, de modo explícito o implícito, a una totalidad de naciones que integran esa realidad cultural llamada "latinoamericana"'. Y advierte no sin ironía: "Si sólo en relación con una de ellas hubo necesidad de especificación, es porque hay problemas al respecto". Candido conoce perfectamente que "cuando se menciona la 'nueva narrativa latinoamericana' se piensa casi exclusivamente en la producción en verdad impresionante de todos los autores esparcidos en todos los países de América que hablan la lengua española" (énfasis en el original), esa "unidad heterogénea, maciza y poderosa, frente a la cual, en una segunda instancia, se recuerda que existe una unidad simple que habla portugués y es preciso incluir, para completar el panorama. Y entonces se reúnen algunos nombres, en general Guimarães Rosa y Clarice Lispector", (82) que vendrían a funcionar como aliciente para compensar el olvido que padece, desde el ámbito hispano, la otra mitad de nuestro subcontinente.

A las preocupaciones ya señaladas -la pretensión de integrar a Brasil con su entorno inmediato, el reconocimiento de la herencia africana en nuestras historia y culturadebemos sumar otra que también emerge en la obra de Candido. "La ciencia y el arte en el contexto universitario latinoamericano y caribeño. El papel que desempeñan los centros e instituciones culturales y docentes", reflexión que la revista Casa de las Américas reprodujo en su número doble 155-156, de 1986, puede servirnos de ejemplo. Expresa allí que "no es a través de las reminiscencias de la Ilustración, tan estimada por el liberalismo burgués, que podremos dar validez humana a las instituciones de cultura superior", sino "por medio de la lucha popular a favor de una inversión estructural que permita romper el ritmo de la danza macabra de los extremos" (77).

Es decir, la variable de clase social resulta clave para entender nuestros dilemas estructurales e intentar resolverlos. "Si quisiéramos utilizar la terminología romántica de nuestros orígenes nacionales", considera el crítico, "diríamos que la tarea en la América Latina es liberar la dimensión utópica de la Ilustración por medio de los movimientos populares que obtengan, finalmente, la difusión del saber". Y así como "las revoluciones de la Independencia se canalizaron hacia las clases dominantes, que interpretaron a su favor lo que había de elitismo supuestamente redentor en la Ilustración", "las de nuestro tiempo deberán mostrar que las posibilidades de saber tienen que abrirse en un final para todos, a través de las luchas sociales y políticas adecuadas". Por lo tanto, expresa, "las reformas estructurales son las que permiten las verdaderas reformas de la enseñanza" (77). Candido no duda del alto nivel intelectual de muchas universidades e instituciones de su país, pero entiende que tal valor no adquiere una dimensión emancipadora mientras esté levantado sobre la exclusión de las masas, a las que necesariamente deberá incorporar.

En ese sentido me parece útil cerrar estas breves notas con el último de los textos de Candido aparecido en la revista Casa, si bien posteriormente se publicó la entrevista 
que le realizara Jorge Ruedas de la Serna, “Antonio Candido: Cómo y por qué escribí Formação da literatura brasileira" (número 268, 2012). Me refiero a la nota que escribió a la muerte de Darcy Ribeiro, publicada en Folha de São Paulo con el título de "As três bandeiras", y que la revista cubana editaría con el de "Las banderas de Darcy Ribeiro" (en el número 207, de 1997). Dice allí Candido que "Darcy Ribeiro siempre tuvo el don de sorprender y disentir", de manera que parece sorprenderle que este "hombre innovador y combativo, maestro irreverente del desacato, quis[iera], sin embargo, ser velado en el espacio convencional de la Academia Brasileña”. (3) Pero el crítico llama la atención, fundamentalmente, sobre un hecho que considera cargado de simbolismo, en referencia a las tres banderas que cubrían el ataúd de Ribeiro: la de Brasil, la de Minas Gerais y la de los sin tierra, pues esta - comenta Candido- modificaba el sentido de las otras dos; "hermanadas a la tercera, no encarnaban el país oficial ni eran pendones de fiesta cívica, objetos agotados de discursos en ceremonias mineras. Mezcladas con la bandera de los espoliados, que luchan por sobrevivir, representaban también al país de los pobres", añadía. Lo que dice entonces Candido sobre Darcy -y es con lo que deseo terminar, para que este ideal suyo no sea olvidado al acercarnos a su descomunal trabajo intelectual- es válido para sí mismo: "las tres banderas mostraban de qué manera Darcy Ribeiro era patriota. Manera especial de los socialistas, de los que sólo entienden la patria como espacio que abarque a todos y a todos asegure el derecho de vivir decentemente" (4).

\section{BIBLIOGRAFÍA}

Candido, Antonio. “Las banderas de Darcy Ribeiro”. Casa de las Américas 207 (1997): 3-4. "Los brasileños y la literatura latinoamericana". Casa de las Américas 136 (1983): $82-92$.

"La ciencia y el arte en el contexto universitario latinoamericano y caribeño. El papel que desempeñan los centros e instituciones culturales y docentes". Casa de las Américas 155-156 (1986): 74-77.

"Discurso en el acto de constitución del jurado". Casa de las Américas 126 (1981): 5-8. "Lucidez latinoamericana". Casa de las Américas 192 (1993): 14-15.

Respuesta a "Encuesta". Casa de las Américas 114 (1979): 21.

Rama, Ángel. La novela en América Latina. Panoramas 1920-1980. [Bogotá]: Procultura / Instituto Colombiano de Cultura, 1982. 